\title{
D-Dimer: a Role in Ruling out Pulmonary Embolism in an Emergency Care Department
}

\author{
Renata Hadžić, ${ }^{1}$ Žana M Maksimović,, ${ }^{2,3}$ Mladen Stajić, ${ }^{2,3}$ Dragana Lončar-Stojiljković ${ }^{4}$
}

\section{Abstract}

Background/Aim: Pulmonary embolism (PE) is a diagnostic challenge, particularly in prehospital care. The aim of this study was to determine to what extent the evaluation of $\mathrm{D}$-dimer value helps physicians with differentiation of $\mathrm{PE}$ and whether D-dimer values are in correlation with the values of revised Geneva score. Methods: Data have been collected for the patients whose D-dimer has been evaluated at the Emergency Care Department of the City of Banja Luka in 2018. Gender, age, symptoms, working diagnosis and D-dimer value have all been recorded and also the fact whether the patient was referred to hospital treatment or not. For each patient the revised Geneva score was determined.

Results: Sixty-eight tests were done in 2018. Out of 68 tests, 41 were negative (60.3\%). D-dimer results helped in making decisions about referring patients to the hospital or not $\left(\chi^{2}=36.32, p<0.001\right)$. Patients with elevated D-dimer levels, especially where the values were four times higher than the refence ones typically were referred to hospital treatment, whereas $67.5 \%$ patients with negative D-dimer results were sent home after giving a treatment and advice. In the elderly patients $\mathrm{D}$-dimer was statistically more positive $(\mathrm{F}=10.82, \mathrm{p}<0.001)$. Values of $\mathrm{D}$-dimer were not significantly different regarding gender $\left(\chi^{2}=2.19, p=0.33\right)$. According to the results of the revised Geneva score, $5.1 \%$ of patients had high risk of PTE, while moderate and low risk had $47.5 \%$ each. Although it has been found that the values of D-dimer were slightly more elevated at higher values of the revised Geneva score and that the difference was not statistically significant $\left(\chi^{2}=7.71, p=0.10\right)$.

Conclusion: Values of D-dimer considerably helped in differentiation of PE in the Emergency Care Department. D-dimer has a high negative predictive value and should be used to exclude PE diagnosis for patients with low clinical probability of PE.

Key words: D-dimer, pulmonary embolism, revised Geneva score, emergency care department.
(1) Emergency Care Deparment, Primary Healthcare Centre Banja Luka, the Republic of Srpska, Bosnia and Herzegovina.

(2) Centre for Biomedical Research, Faculty of Medicine, University of Banja Luka, Banja Luka, the Republic of Srpska, Bosnia and Herzegovina.

(3) Primary Healthcare Centre Modriča, Modriča, the Republic of Srpska, Bosnia and Herzegovina.

(4) Department of Anaesthesiology and Intensive Therapy, Institute for Cardiovascular Diseases "Dedinje", Belgrade, Serbia.

Correspondence:

ŽANA M MAKSIMOVIĆ

E: maksimoviczana85@gmail.com M: +38765970 593

\section{ARTICLE INFO}

Received: 29 February 2020 Revision received: 12 March 2020 Accepted: 13 March 2020

\section{Introduction}

Pulmonary embolism (PE) is one of the most difficult conditions to diagnose, particularly in the prehospital care. It represents the most serious clinical manifestation of venous thromboembolism (VTE), which represents the third most common cardiovascular disease. ${ }^{1-4}$ The main cause of PE-related deaths is the undiagnosed PE during lifetime (59 \%), followed by sudden fatal PE (34\%). It is estimated that only $7 \%$ of patients who died from PE had PE diagnosed on time. $^{5-7}$ Frequency of PE is hard to determine because it can sometimes remain asymptomatic and therefore go unsuspected, while on the other hand PE is often accidentally diagnosed as an incidental finding. ${ }^{8}$ 
$\mathrm{PE}$ is one of the most urgent conditions in medicine. The success of treatment largely depends on timely diagnosis. PE primarily needs to be thought of, and early diagnosis and treatment of patients is possible if PE is suspected on the basis of detailed anamnestic data. Many risk factors can raise suspicion about PE, however it can happen without any of the predisposing factors (up to $30 \%$ ). ${ }^{9}$ Clinical manifestation of $\mathrm{PE}$ is also nonspecific, so dyspnoea, as the most common symptom/sign of PE, occurs in only $50 \%$ of the clinically confirmed PEs. ${ }^{10,11}$ A clinical probability for PE is estimated on the basis of clinical presentation by using the Wells clinical decision rule or the revised Geneva score. $^{12-16}$

The electrocardiographic (ECG) changes are miscellaneous and usually nonspecific (most common is sinus tachycardia, followed by the right bundle branch block - RBBB, turning of heart axis to the right, SI QIII TIII, P pulmonale, simultaneous inversion of $\mathrm{T}$ waves in inferior and right precordial leads), but in $18 \%$ of patients ECG is normal. ${ }^{17,18}$ Nonspecific changes or lack of them can also be found during the physical check-up, chest X-ray and laboratory tests. ${ }^{7,19,20}$ Gold standard for the diagnosis of PE is computed tomography (CT)-pulmonary angiography and/or ventilation-perfusion (VQ) scan. ${ }^{21,22}$

D-dimer is a fibrin degradation product, a small protein fragment present in the blood after fibrinolysis. Role of D-dimer is to exclude the PE diagnosis. ${ }^{23-25} \mathrm{D}$-dimer plasma levels are elevated in patients with acute thrombosis because of the simultaneous activation of coagulation and fibrinolysis. ${ }^{26}$ Negative predictive D-dimer value is high (95-98 \%) and PE with normal values of D-dimer is unlikely. On the other hand, fibrin is produced in other conditions including cancer, inflammation, bleeding, trauma, necrosis and surgical intervention. ${ }^{27-29}$ Therefore, positive predictive $\mathrm{D}$-dimer value is low and elevated $\mathrm{D}$-dimer le-vels are not useful in confirmation of PE..$^{30} 3^{11}$ This implies recommendations that the patients with highly suspected PE should immediately undergo CT-pulmonary angiography and skip the D-dimer testing. ${ }^{9}$, 32,33

The aim of this study was to determine to what extent D-dimer values help to differentiate PE in emergency care departments and therefore help in making a decision to transfer patients to a higher referential level or not. Furthermore, the aim was to determine whether the $\mathrm{D}$-dimer values correlated with the values of revised Geneva score.

\section{Methods}

The protocol of the study was approved by the Ethics Committee of the Primary Medical Centre Banja Luka and all the efforts were undertaken in order to keep the anonymity of the included patients.

Following the protocol of the Emergency Care Department of the City of Banja Luka, data were found for all the patients in whom the D-dimer was tested in 2018. Gender has been recorded (female/male), age, symptoms, D-dimer level $(\mathrm{mg} / \mathrm{L})$, working diagnosis, and data whether the patient was referred to the hospital treatment or not. Patients' anonymity was preserved, while only gender and age were recorded, excluding other personal data.

The D-dimer values have been analysed by a quantitative, latex-enhanced immunoturbidimetric immunoassay on Cobas h-232 system. Although D-dimer has only one cut-off value, the authors were interested in finding to what extent a D-dimer value affected the physician's decision, ie, if there was a difference whether a D-dimer value was slightly elevated or if it was four times or more higher than referential value. Therefore, a value of $\mathrm{D}$-dimer was recorded in two ways, as a numeric value and as a value in one of three categories: $<0.5 \mathrm{mg} / \mathrm{L}, \geq 0.5-2$ $\mathrm{mg} / \mathrm{L}$ and $\geq 2 \mathrm{mg} / \mathrm{L}$.

Table 1. Geneva score: clinical prediction rules for pulmonary embolism

\begin{tabular}{|c|c|}
\hline Variable & Points \\
\hline \multicolumn{2}{|l|}{ RISK FACTORS } \\
\hline Age 65 or over & 1 \\
\hline Previous DVT or PE & 3 \\
\hline Surgery or fracture within 1 month & 2 \\
\hline Active malignant condition & 2 \\
\hline \multicolumn{2}{|l|}{ SYMPTOMS } \\
\hline Unilateral lower limb pain & 3 \\
\hline Haemoptysis & 2 \\
\hline \multicolumn{2}{|l|}{ CLINICAL SIGNS } \\
\hline Heart rate: $75-94 / \mathrm{min}$ & 3 \\
\hline$\geq 95 / \mathrm{min}$ & 5 \\
\hline Pain on deep palpation of lower limb and unilateral edema & 4 \\
\hline \multicolumn{2}{|l|}{ CLINICAL PROBABILITY } \\
\hline Low & $0-3$ \\
\hline Intermediate & $4-10$ \\
\hline High & $\geq 10$ \\
\hline
\end{tabular}

Using the anamnestic data, symptoms, clinical signs, age and gender of the patient, for each patient the revised Geneva score was calculated. The parameters set for Geneva score are listed in 
Table $1{ }^{14}$ Based on the values of Geneva score, patients were allocated into one of three categories: with low, intermediate or high clinical probability for PE.

Results were processed by using IBM SPSS 21.0 software. Categorial data were analysed by Chisquare test and age, after distribution uniformity was verified, by one-way analysis of variance (ANOVA). The average D-dimer values were distributed by the Man-Whitney U test, or the Kruskal-Wallis test.

\section{Results}

Sixty-eight tests were done in the Emergency Care Department of the City of Banja Luk a in 2018. Of 68 tests, 41 were negative $(60.29 \%)$, meaning that it was less than $0.5 \mathrm{mg} / \mathrm{L}$; from 0.5 up to $2 \mathrm{mg} / \mathrm{L}$ there were 19 tests (13.23\%), and over $2 \mathrm{mg} / \mathrm{L}$ there were 8 tests (11.76\%). Patients' characteristics are shown in Table 2.

The mean age of the patients was $60.3( \pm 17.4)$ years, with $45.5 \%$ patients being older than 65. Levels of D-dimer were statistically significantly higher in elderly people (Kruskal-Wallis test: $\left.\chi^{2}=12.96, p=0.002\right)$. Also, by analysing the ratio of positive and negative values of the

Table 2. Distribution of gender, age and D-dimer values

\begin{tabular}{|c|c|c|c|c|c|}
\hline \multirow{2}{*}{ Variable } & \multirow{2}{*}{ N (\%) } & \multicolumn{2}{|c|}{ D-dimer } & \multirow[t]{2}{*}{ Test } & \multirow{2}{*}{$p$-value } \\
\hline & & Mean (SD) & $95 \% \mathrm{Cl}$ & & \\
\hline \multicolumn{6}{|l|}{ GENDER } \\
\hline Male & $30(44.12 \%)$ & $0.77(0.99)$ & $0.40-1.14$ & & \\
\hline Female & $38(55.88 \%)$ & $0.80(0.93)$ & $0.49-1.10$ & $U=479.50^{*}$ & ${ }^{*} 0.264$ \\
\hline \multicolumn{6}{|c|}{ AGE (years) } \\
\hline$<40$ & $12(17.65 \%)$ & $0.47(0.93)$ & $0.11-1.06$ & & \\
\hline $41-65$ & $25(36.76 \%)$ & $0.55(0.59)$ & $0.32-0.79$ & & \\
\hline$>65$ & $31(45.59 \%)$ & $1.21(1.14)$ & $0.75-1.66$ & $\chi=12.96^{* *}$ & * 0.002 \\
\hline TOTAL & 68 (100.00 \%) & $0.79(0.95)$ & $0.55-1.02$ & & \\
\hline
\end{tabular}

D-dimer, the frequent D-dimer was significantly more positive in elderly people (One-way ANOVA: $F=10.82, p<0.001)$.

There were 30 men (44.12 \%) and 38 women $(55.88 \%)$. The ratio of positive and negative results of the D-dimer tests was without significant difference with respect to gender (Chi square test: $\chi^{2}=2.19, \mathrm{p}=0.33$ ), as was the average value of the $\mathrm{D}$-dimer itself (Man-Whitney $\mathrm{U}$ test: $\mathrm{U}=479.50, \mathrm{p}=0.264$ )
The most common symptoms/signs in patients for whom D-dimer level were determined were: dyspnoea (37.3\%), chest pain (25.4\%), heart rate over 90 per minute $(20.39 \%)$, cough $(15.25$ $\%)$, pain and leg oedema (15.25\%), nausea (11.86 $\%)$, fever (11.86 \%) and syncope (10.17\%). Anamnestically, $3.36 \%$ of patients had previous surgeries and $3.36 \%$ of patients had deep vein thrombosis or pulmonary embolism.

According to the Geneva score, $5.08 \%$ of patients were at high risk of PTE and $47.46 \%$ at intermediate or low risk each. Although the D-dimer values were found slightly higher at the higher Geneva score values, the difference was

Table 3. Correlation between the revised Geneva score and D-dimer values

\begin{tabular}{|c|c|c|c|c|}
\hline $\begin{array}{l}\text { D-dimer } \\
\text { (mg/L) }\end{array}$ & $\begin{array}{l}\text { Revised Gene } \\
\text { Low - N (\%) }\end{array}$ & $\begin{array}{l}\text { eva score-Clinice } \\
\text { Interm. - N (\%) }\end{array}$ & $\begin{array}{r}\text { al probability } \\
\text { High - N (\%) }\end{array}$ & $\begin{array}{l}\text { Total } \\
\text { N (\%) }\end{array}$ \\
\hline$<0.5$ & $21(75.00 \%)$ & $13(46.43 \%)$ & $1(33.33 \%)$ & $35(59.32 \%)$ \\
\hline $0.5-2$ & $6(21.43 \%)$ & $10(35.71 \%)$ & $2(66.67 \%)$ & $18(30.51 \%)$ \\
\hline$\geq 2$ & $1(3.57 \%)$ & $5(17.86 \%)$ & $0(0.00 \%)$ & $6(10.17 \%)$ \\
\hline TOTAL & $28(47.46 \%)$ & $28(47.46 \%)$ & $3(5.08 \%)$ & $59(100.00 \%)$ \\
\hline
\end{tabular}

not statistically significant $\left(\chi^{2}=7.71, p=0.10\right)$ (Table 3).

Half of the patients analysed for the D-dimer were not referred for further hospital treatment (48.48 \%). On suspicion of PE, $27.27 \%$ of patients were referred for further hospital treatment and other patients were referred, but under a different diagnosis. The $\mathrm{D}$-dimer values helped in making the decision whether to refer a patient to hospital treatment or not $\left(x^{2}=36.32\right.$, $\mathrm{p}<0.001)$.

Table 4. Effect of D-dimer on decision to refer for further hospital treatment

\begin{tabular}{|c|c|c|c|c|}
\hline \multirow{2}{*}{$\begin{array}{l}\text { D-dimer } \\
\text { (mg/L) }\end{array}$} & \multicolumn{3}{|c|}{ Referred to the hospital } & \multirow[t]{2}{*}{ Total } \\
\hline & No & Yes & Yes, diff. $\mathrm{Dg}^{\star}$ & \\
\hline$<0.5$ & $27(67.50 \%)$ & $2(5.00 \%)$ & $11(27.50 \%)$ & $40(60.60 \%)$ \\
\hline $0.5-2$ & $5(27.78 \%)$ & $8(44.44 \%)$ & $5(27.78 \%)$ & $18(27.27 \%)$ \\
\hline$\geq 2$ & $0(00.00 \%)$ & $8(100.00 \%)$ & $0(00.00 \%)$ & $8(12.12 \%)$ \\
\hline TOTAL & 32 (48.48 \%) & 18 ( $27.27 \%)$ & 16 (24.24 \%) & $66(100.00 \%)$ \\
\hline
\end{tabular}

Patients who were found to have high D-dimer values, especially where they were four times more the cut-off values, were generally referred for hospital treatment, while $67.50 \%$ of patients with negative $\mathrm{D}$-dimer values were returned home after receiving treatment and advice (Table 4). 


\section{Discussion}

In 2018, 68 D-dimer analyses were performed at the Emergency Care Department of the City of Banja Luka. The assumption is that the need for analyses was greater, but unfortunately analyses are not continuously available. For this reason, it was decided to analyse only patients who had done the D-dimer test, because if all patients who were suspected on PE or with dyspnoea had been analysed, an unrealistically low percentage of patients in whom D-dimer was determined would had been obtained.

Two thirds of the tests were negative $(<0.5$ $\mathrm{mg} / \mathrm{L})$. A high percentage of patients who are $\mathrm{D}$-dimer-negative is logical, since the $\mathrm{D}$-dimer is primarily used to rule out the diagnosis of $\mathrm{PE}$ and deep vein thrombosis. ${ }^{30}$ The $\mathrm{D}$-dimer was significantly higher in elderly patients, which is in accordance with the results of other studies. There are also recommendations to adjust the cut-off value of the $\mathrm{D}$-dimer according to age by adding 0.1 to $0.5 \mathrm{mg} / \mathrm{L}$ for every 10 years of age for people over $50 .{ }^{34-36}$ This is thought to increase the specificity of the $\mathrm{D}$-dimer in the elderly. ${ }^{37-39}$

Clinical studies indicate that the D-dimer values are slightly higher in women, which is in accordance with the results of this study. As was the case with the results of other researchers, the difference was not significant in the present study either. The difference in D-dimer values in men and women is considered to be of no clinical significance and it is not recommended to correct the cut-off values based on gender. ${ }^{39}$ However, some researchers believe that D-dimer values should be adjusted for both gender and age, with multiple cut-off values, in order to significantly improve the specificity of D-dimer testing..$^{40}$ In contrast to the $\mathrm{D}$-dimer values, $\mathrm{PE}$ itself is slightly more common in men. ${ }^{41}$ The results of this study show that women were slightly more frequently diagnosed with PE (30 \% : $20 \%$ of patients), which could be explained by the fact that no cut-off corrections were made for women and therefore there was a higher percentage of false-positive tests in female patients.

The Wells score and the Geneva score were introduced in an attempt to adequately suspect or exclude PE based on history, symptoms and clinical presentation. ${ }^{42}$ Clinical trials indicate that the significance of the revised Geneva score is primarily in the exclusion of $\mathrm{PE}$ combined with low D-dimer values. ${ }^{43,44}$ The results of this study indicate that the revised Geneva score values did not influence physicians' decision not to refer such patients for further treatment, but only the D-dimer values. Analysis from other studies also implies underuse of clinical decision rules. 45 There was a correlation between the revised Geneva score and the D-dimer, but it was not statistically significant. However, given a relatively small sample, it would be assumed that with a sufficiently large sample statistical significance would be reached. It is also the authors' belief that when deciding whether to refer a patient for further hospital treatment or not, physicians should consider the revised Geneva score, especially if its value is $<3 . .^{46,47}$ Intermediate-risk PE patients present a diagnostic and therapeutic dilemma. ${ }^{48}$ Besides, research results indicate that in older, high-risk patients, the Wells scores are more in correlation with the diagnosis of $\mathrm{PE}$ than the revised Geneva score. ${ }^{49-51}$

The D-dimer values significantly aided the physicians' decision to refer the patient to further hospital treatment under the diagnosis of PE. When $\mathrm{D}$-dimer values were $<0.5 \mathrm{mg} / \mathrm{L}$, twothirds of patients were not referred for further hospital treatment and the others were referred under some other diagnosis. Two patients, despite the negative $\mathrm{D}$-dimer values, were referred under the diagnosis of PE and this is, in fact, an example of poor clinical practice. The reason is that if the low $\mathrm{D}$-dimer value does not alter the physician's opinion that it is $\mathrm{PE}$ or not, the $\mathrm{D}$-dimer should not been tested at all. On the other hand, half of the patients with D-dimer values $>0.5$ and all patients with values $>2 \mathrm{mg} / \mathrm{L}$ were referred for further treatment and diagnosis.

\section{Conclusion}

The very purpose of the D-dimer and revised Geneva score is to exclude PE and reduce unnecessary imaging diagnostic procedures, such as CT-pulmonary angiography and similar. The fact that the test results are available after 20 minutes should also not be overlooked, given that the speed of diagnosis and patient treatment is one of the key factors in working in an emergency care department. 


\section{Acknowledgements}

None.

\section{Conflict of interest}

None.

\section{References}

1. Bradbury C, Fletcher K, Sun Y, Heneghan C, Gardiner C, Roalfe A, et al. A randomised controlled trial of extended anticoagulation treatment versus standard treatment for the prevention of recurrent venous thromboembolism (VTE) and post-thrombotic syndrome in patients being treated for a first episode of unprovoked VTE (the ExACT study). Br J Haematol 2019 Nov 12. doi: 10.1111/bjh.16275.

2. Parakh RS, Sabath DE. Venous Thromboembolism: Role of the Clinical Laboratory in Diagnosis and Management. J Appl Lab Med 2019;3(5):870-82.

3. Benjamin EJ, Blaha MJ, Chiuve SE, Cushman M, Das SR, Deo R, et al; American Heart Association Statistics Committee and Stroke Statistics Subcommittee. Heart Disease and Stroke Statistics-2017 Update: A Report From the American Heart Association. Circulation 2017 Mar 7;135(10):e146-e603. doi: 10.1161/ CIR.0000000000000485.

4. Konstantinides SV, Torbicki A, Agnelli G, Danchin N, Fitzmaurice D, Galiè N, et al; Task Force for the Diagnosis and Management of Acute Pulmonary Embolism of the European Society of Cardiology (ESC). 2014 ESC Guidelines on the diagnosis and management of acute pulmonary embolism. Eur Heart J 2014;35(43):303369.

5. Cohen AT, Agnelli G, Anderson FA, Arcelus JI, Bergqvist D, Brecht JG, et al. Venous thromboembolism (VTE) in Europe. The number of VTE events and associated morbidity and mortality. Thromb Haemost 2007;98(4):756-64.

6. Rubini G, Ferrari C, Cimino A, Fanelli M, Altini C, Gaudiano A, et al. How often suspected pulmonary embolism is diagnosed and its main diagnostic characteristics, in an emergency nuclear medicine service? Four years experience. Hell J Nucl Med 2019;22(3):187-93.

7. Kausar S, Khan HS, Nazir MTB, Adeel-Ur-Rehman, Kayani AM. Acute pulmonary embolism: presentation, diagnosis, management and factors impacting clinical outcome in a tertiary cardiac centre in Pakistan. $\mathrm{J}$ Coll Physicians Surg Pak 2019;29(8):749-52.

8. 8. Alotaibi GS, Wu C, Senthilselvan A, McMurtry MS. Secular trends in incidence and mortality of acute venous thromboembolism: The AB-VTE population-based study. Am J Med 2016 Aug;129(8):879.e1925. doi: 10.1016/j.amjmed.2016.01.041.

9. Bozorgmehr R, Pishgahi M, Mohaghegh P, Bayat M, Khodadadi P, Ghafori A. Relationship between thrombosis risk factors, clinical symptoms, and laborato- ry findings with pulmonary embolism diagnosis; a cross-sectional study. Arch Acad Emerg Med 2019 Jul 23;7(1):41. eCollection 2019.

10. Pollack CV, Schreiber D, Goldhaber SZ, Slattery D, Fanikos J, O’Neil BJ, et al. Clinical characteristics, management, and outcomes of patients diagnosed with acute pulmonary embolism in the emergency department: initial report of EMPEROR (Multicenter Emergency Medicine Pulmonary Embolism in the RealWorld Registry). J Am Coll Cardiol 2011;57(6):700-6.

11. Badertscher P, du Fay de Lavallaz J, Hammerer-Lercher A, Nestelberger T, Zimmermann T, Geiger M, et al; BASEL IX Investigators. Prevalence of pulmonary embolism in patients with syncope. J Am Coll Cardiol 2019;74(6):744-54.

12. Gibson NS, Sohne M, Kruip MJ, Tick LW, Gerdes V, Bossuyt PM, et al. Further validation and simplification of the Wells clinical decision rule in pulmonary embolism. Thromb Haemost 2008;99(1):229-34.

13. Le Gal G, Righini M, Roy P-M, Sanchez O, Aujesky D, Bounameaux $\mathrm{H}$, et al. Prediction of pulmonary embolism in the emergency department: the revised Geneva score. Ann Intern Med 2006;144:165-71.

14. Klok FA, Mos ICM, Nijkeuter M, Righini M, Perrier A, Le Gal G, et al. Simplification of the revised Geneva score for assessing clinical probability of pulmonary embolism. Arch Intern Med 2008;168(19):2131-36.

15. van Maanen R, Rutten FH, Klok FA, Huisman MV, Blom JW, Moons KGM, et al. Validation and impact of a simplified clinical decision rule for diagnosing pulmonary embolism in primary care: design of the PECAN prospective diagnostic cohort management study. BMJ Open 2019 Oct 10;9(10):e031639. doi: 10.1136/bmjopen-2019-031639.

16. Tak T, Karturi S, Sharma U, Eckstein L, Poterucha JT, Sandoval Y. Acute Pulmonary Embolism: Contemporary Approach to Diagnosis, Risk-Stratification, and Management. Int J Angiol 2019;28(2):100-11.

17. Kosuge M, Kimura K, Ishikawa T, Ebina T, Hibi K, Kusama I, et al. Electrocardiographic differentiation between acute pulmonary embolism and acute coronary syndromes on the basis of negative T waves. Am J Cardiol 2007;99(6):817-21.

18. Ed Burns. EKG changes in pulmonary embolism. Life in the fastline. [Cited 2019 November 19] Available from: https://litfl.com/ecg-changes-in-pulmonary-embolism/

19. Ozdemir M, Sonmez BM, Yilmaz F, Yilmaz A, Duyan $\mathrm{M}$, Komut S. Is bedside end-tidal CO2 measurement a screening tool to exclude pulmonary embolism in emergency department? J Clin Med Res 2019;11(10):696702.

20. van der Pol LM, Tromeur C, Faber LM, van der Hulle T, Kroft LJM, Mairuhu ATA, et al. Chest X-ray not routinely indicated prior to the YEARS algorithm in the diagnostic management of suspected pulmonary embolism. TH Open 2019 Jan 8;3(1):e22-e27. doi: 10.1055/ s-0038-1676812. eCollection 2019 Jan.

21. Beenen LFM, Bossuyt PMM, Stoker J, Middeldorp S. Prognostic value of cardiovascular parameters in computed tomography pulmonary angiography in patients with acute pulmonary embolism. Eur Respir J 2018;52(1) pii: 1702611. doi: 10.1183/13993003.026112017.

22. Kruger PC, Eikelboom JW, Douketis JD, Hankey GJ. Pulmonary embolism: update on diagnosis and management. Med J Aust 2019;211(2):82-7.

23. Oi M, Yamashita Y, Toyofuku M, Morimoto T, Moto- 
hashi Y, Tamura T, et al; COMMAND VTE Registry Investigators. $\mathrm{D}$-dimer levels at diagnosis and long-term clinical outcomes in venous thromboembolism: from the COMMAND VTE Registry. J Thromb Thrombolysis 2019 Sep 30. doi: 10.1007/s11239-019-01964-0. [Epub ahead of print]

24. Lucassen W, Geersing GJ, Erkens PM, Reitsma JB, Moons KG, Büller $\mathrm{H}$, et al. Clinical decision rules for excluding pulmonary embolism: a meta-analysis. Ann Intern Med 2011;155(7):448-60.

25. Geersing GJ, Zuithoff NPA, Kearon C, Anderson DR, Ten Cate-Hoek AJ, Elf JL, et al. Exclusion of deep vein thrombosis using the Wells rule in clinically important subgroups: individual patient data meta-analysis. BMJ 2014 Mar 10;348:g1340. doi: 10.1136/bmj.g1340.

26. Tasić N, Paixão TRLC, Gonçalves LM. Biosensing of D-dimer, making the transition from the central hospital laboratory to bedside determination. Talanta 2020 Jan 15;207:120270. doi: 10.1016/j.talanta.2019.120270. Epub 2019 Aug 16.

27. Rotzinger DC, Dunet V, Ilic V, Hugli OW, Meuli RA, Schmidt S. Pulmonary embolism during pregnancy: a 17-year single-center retrospective MDCT pulmonary angiography study. Eur Radiol 2019 Nov 14. doi: 10.1007/s00330-019-06501-4.

28. Guo J, Deng QF, Xiong W, Pudasaini B, Yuan P, Liu JM et al. Comparison among different presentations of venous thromboembolism because of lung cancer. Clin Respir J 2019;13(9):574-82.

29. Polo Friz H, Pezzetti V, Orenti A, Caleffi A, Corno V, Crivellari C, et al. Comorbidity burden conditions the prognostic performance of D-dimer in elderly patients with acute pulmonary embolism. Am J Emerg Med 2019;37(5):799-804.

30. Vögeli A, Ghasemi M, Gregoriano C, Hammerer A, Haubitz S, Koch D, et al. Diagnostic and prognostic value of the $\mathrm{D}$-dimer test in emergency department patients: secondary analysis of an observational study. Clin Chem Lab Med 2019;57(11):1730-6.

31. Rawat N, Mathur N, Rawat K, Mathur M, Tinna R, Kakkar R et al. Correlation of D-Dimer Level with the Presence and Severity of Pulmonary Embolism on Computed Tomography Pulmonary Angiography. J Assoc Physicians India 2018;66(10):40-1.

32. 32. Tran HA, Gibbs H, Merriman E, Curnow JL, Young L, Bennett A et al. New guidelines from the Thrombosis and Haemostasis Society of Australia and New Zealand for the diagnosis and management of venous thromboembolism. Med J Aust 2019;210(5):227-35.

33. Wells PS, Anderson DR, Rodger M, Stiell I, Dreyer JF, Barnes D, et al. Excluding pulmonary embolism at the bedside without diagnostic imaging: management of patients with suspected pulmonary embolism presenting to the emergency department by using a simple clinical model and d-dimer. Ann Intern Med 2001;135(2):98-107.

34. Reardon PM, Patrick S, Taljaard M, Thavorn K, Nemnom MJ, Mukarram M, et al. Diagnostic Accuracy and Financial Implications of Age-Adjusted D-Dimer Strategies for the Diagnosis of Deep Venous Thrombosis in the Emergency Department. J Emerg Med 2019;56(5):469-477.

35. Dutton J, Dachsel M, Crane R. Can the use of an age-adjusted D-dimer cut-off value help in our diagnosis of suspected pulmonary embolism? Clin Med (Lond) 2018;18(4):293-6.

36. Barth BE, Waligora G, Gaddis GM. Rapid Systematic
Review: Age-Adjusted D-Dimer for Ruling Out Pulmonary Embolism. J Emerg Med 2018;55(4):586-92.

37. Ortiz J, Saeed R, Little C, Schaefer S. Age-Adjusted D-Dimer in the prediction of pulmonary embolism: does a normal age-adjusted D-dimer rule out PE? Biomed Res Int 2017; 2017: 4867060. Epub 2017 Oct 19.

38. Righini M, Van Es J, Den Exter PL, Roy PM, Verschuren F, Ghuysen A, et al. Age-adjusted D-dimer cutoff levels to rule out pulmonary embolism: the ADJUST-PE study. JAMA 2014;311(11):1117-24.

39. Haase C, Joergensen M, Ellervik C, Joergensen MK, Bathum L. Age- and sex-dependent reference intervals for D-dimer: evidence for a marked increase by age. Thromb Res 2013;132(6):676-80.

40. Legnani C, Cini M, Cosmi B, Carraro P, Tripodi A, Erba $\mathrm{N}$, et al. Age and gender specific cut-off values to improve the performance of $\mathrm{D}$-dimer assays to predict the risk of venous thromboembolism recurrence. Intern Emerg Med 2013;8(3):229-36.

41. Giordano NJ, Jansson PS, Young MN, Hagan KA, Kabrhel C. Epidemiology, pathophysiology, stratification, and natural history of pulmonary embolism. Tech Vasc Interv Radiol 2017;20(3):135-40.

42. Kline JA. Diagnosis and exclusion of pulmonary embolism. Thromb Res 2018;163:207-20.

43. Ishimaru N, Ohnishi H, Yoshimura S, Kinami S. The sensitivities and prognostic values of the Wells and revised Geneva scores in diagnosis of pulmonary embolism in the Japanese population. Respir Investig 2018;56(5):399-404.

44. Szturmowicz M, Kacprzak A, Wyrostkiewicz D, Lewandowska K, Jędrych M, Bartoszuk I, et al. Non-high risk PE in the patients with acute or exacerbated respiratory disease: the value of the algorithm based on D-dimer evaluation and Revised Geneva Score. Pneumonol Alergol Pol 2015;83(6):445-52.

45. Hsu N, Soo Hoo GW. Underuse of clinical decision rules and D-dimer in suspected pulmonary embolism: a nationwide survey of the Veterans Administration Health Care System. J Am Coll Radiol 2020;17(3):405-11.

46. Kim YJ, Choi DH, Lee ES, Ryoo SM, Ahn S, Sohn CH, et al. Utility of the simplified Wells and revised Geneva scores to exclude pulmonary embolism in femur fracture patients. Am J Emerg Med 2017;35(8):1131-5.

47. Kearon C, de Wit K, Parpia S, Schulman S, Afilalo M, Hirsch A, et al. Diagnosis of pulmonary embolism with d-Dimer adjusted to clinical probability. N Engl J Med 2019;381(22):2125-34.

48. Beigel R, Mazin I, Goitein O, Herscovici R, Natanzon $\mathrm{S}$, Chernomordik $\mathrm{F}$, et al. Intermediate-risk pulmonary embolism: aiming to improve patient stratification. Eur J Intern Med 2019;65:32-6.

49. Di Marca S, Cilia C, Campagna A, D'Arrigo G, Abd ElHafeez S, Tripepi G, et al. Comparison of Wells and Revised Geneva Rule to assess pretest probability of pulmonary embolism in high-risk hospitalized elderly adults. J Am Geriatr Soc 2015;63(6):1091-7.

50. Guo DJ, Zhao, Zou YD, Huang XH, Hu JM, Guo L. Values of the Wells and revised Geneva scores combined with D-dimer in diagnosing elderly pulmonary embolism patients. Chin Med J (Engl) 2015;128(8):1052-7.

51. Shen JH, Chen HL, Chen JR, Xing JL, Gu P, Zhu BF. Comparison of the Wells score with the revised Geneva score for assessing suspected pulmonary embolism: a systematic review and meta-analysis. J Thromb Thrombolysis 2016;41(3):482-92. 